\title{
Teacher Beliefs About Sustainable Agriculture: A Self-made Measurement Scale
}

\author{
Mathew Muma ${ }^{1}$, Robert Martin ${ }^{1}$, \& Mack Shelley ${ }^{2}$ \\ ${ }^{1}$ Iowa State University, Agricultural Education and Studies, Ames, USA \\ ${ }^{2}$ Department of Statistics and Department of Political Science, 539 Ross Hall, Ames, USA \\ Correspondence: Mathew Muma, Kenya Institute for Public Policy Research and Analysis, 2nd Floor, Bishops \\ Garden Towers, P O Box 56445-00200, Nairobi, Kenya. Tel: 254-70-030-5115. E-mail: mumadr@gmail.com
}

Received: May 14, $2020 \quad$ Accepted: September 10, $2020 \quad$ Online Published: October 31,2020

doi:10.5539/ass.v16n11p115 URL: https://doi.org/10.5539/ass.v16n11p115

\begin{abstract}
The study's purpose was to analyze the validity of the construct of a self-made Alternative-Conventional Agricultural Paradigm scale using the teacher population teaching high school agriculture in the North Central Region of the USA. A random sample of 844 teachers was drawn. Teachers were self-administered questionnaires with 5-point Likert-type scales. Instrument inter-item consistency and item coherence were determined. The relatively high coefficient alpha (.82), mean item total correlation (.40), and unrotated first factors with modest number of items loading on the factor means that the scale has mainly one underlying construct. The teacher population holds consistent views and attitudes about SA constituting an agricultural paradigm. The instrument items are coherent as components of a whole and are related. However, the teacher population did not hold stronger paradigmatic views on the scale as can be expected because of their relatively low mean score item-total correlation and coefficient alpha for the instrument compared to what was found for the scale in the Beus and Dunlap (1991) study. This should be expected because agriculture teachers are not strong adherents of the two agricultural paradigms who can be expected to make extreme and polar scores on the scale. The instrument can therefore be used to preliminarily gauge the paradigmatic orientation of agriculture teachers in the region. Further research with the instrument with known groups supporting the two paradigms is necessary to establish its validity.
\end{abstract}

Keywords: agriculture paradigms, agricultural sustainability, conventional agriculture, conventional agriculture paradigm, dominant social paradigm, sustainable agriculture, sustainable agriculture paradigm, sustainable agriculture scale, sustainability measurement, sustainability scale

\section{Introduction}

According to Beus and Dunlap (1990), sustainable agriculture (SA) emerged in the 1980s as a new paradigm of agriculture distinct from conventional agriculture (CA) based on the dominant Western world view that has elevated progress, growth and faith in science and technology in solving any societal problem above everything else (Jackson-Smith \& Buttel, 2003). Consequently much debate about the pros and cons of SA and CA occurred between advocates of the two paradigms of agriculture in the 1980s and beyond. A paradigm is a subset of a belief system and can inform social practices such as farming practices among farmers endorsing SA/CA paradigms. Beus and Dunlap (1991, 1994) developed a scale for Alternative-Conventional Agriculture Paradigm (ACAP) to identify adherence to the two diametrically opposed and polar paradigms. The researchers, Beus and Dunlap (1991), indicated the scale could facilitate a basis of understanding the different positions taken in agricultural debates and possible resolutions of the debates. The scale was also expected to identify the main points of convergence and divergence between proponents and exponents of the two paradigms from relative endorsements of the paradigms (Beus \& Dunlap, 1991). Muma, Martin and Shelley (2011) made a conclusion that the position taken by an individual on a particular paradigm on the scale is expected to translate into behavioral practices in agriculture reflecting the particular paradigm endorsed.

One important area that the need for establishing the unidimensionality/internal consistency for the ACAP scale is necessary is in high school agriculture education. Understanding agriculture teacher positions on the scale would illuminate the extent to which the values and beliefs teachers hold about SA/CA can influence their motivation to teach and help students develop positive attitudes towards SA (Rassmussen \& Kaltoft, 2003) and 
contribute to the goals of SA. This is expected as one's paradigm of agriculture and has effects on their professional knowledge and experience of agriculture and vice versa (Wheeler, 2007). The objective of the study was to assess the construct validity of a self-made ACAP scale using agriculture teacher population of the states in the North Central Region.

The six dimensions of SA/CA used by Beus and Dunlap (1991) in constructing the ACAP scale were distilled from analysis of statements about each paradigm of agriculture made over time by paradigm proponents. The elements were synthesized from the definitions, meanings, structures, policies and practices about agriculture that members of the two camps have advocated for agriculture. Each element has been identified in a pair in which each pair measures polar and opposed beliefs/values about sustainable agriculture and conventional agriculture (Beus \& Dunlap, 1992, 1994 cited in Muma, Martin, Shelley, \& Holmes, 2010). Muma et al., 2010 stated that differences between proponents and exponents of the diametrically opposed paradigms can be assessed by the extent to which a score on the scale is aligned to each element pair as follows: (1) independence versus dependence; (2) centralization versus decentralization; (3) competition versus community; (4) exploitation versus restraint; (5) specialization or diversity; and (6) domination or harmony. A pair of a dimension of SA or an element is an all or none trait which an individual does not necessarily fit into neatly (Beus \& Dunlap, 1990 cited in Muma et al., 2010).

Beus and Dunlap (1991 cited in Muma et al., 2010) validated the scale by matching the expected scores on adherence to SA/CA to farmer/individual organizational affiliation among statewide farmers and members of known groups supporting one or the other of the two paradigms in Washington State, USA such as agricultural chemical dealers. The known groups had relatively stronger polar scores on the instrument compared to the statewide farmers whose scores were in between the two extremes. The instrument achieved an internal consistency defined by a modest mean corrected item-total correlation (.46) and coefficient alpha (.88). The attitudinal variables were assumed to have coherence as interrelated parts of a whole as beliefs in the concept of a paradigm. Endorsement of beliefs about SA among agricultural faculty and students on the one hand (Beus \& Dunlap, 1992; Rasmussen \& Kaltoft, 2003) and adoption of farming practices among farmers on the other have been validated in a number of studies in Canada (Abaidoo \& Dickinson, 2003, 2009), Australia (Rickson, Saffigna \& Sanders, 1999), and the USA (Allen \& Bernhardt, 1995 cited in Welsh \& Rivers, 2011; Beus \& Dunlap, 1994 cited in Welsh \& Rivers, 2011; Chiappe \& Flora, 1998; Petrzelka \& Korsching, 1996). All the studies except that of Petrzelka and Korsching (1996) concluded the ACAP scale could be used to delineate for individuals the polar beliefs about agriculture. However, the researchers indicated that some elements of SA/CA were not as strong as the others in achieving this end.

Chiappe and Flora (1998 cited in Muma et al., 2010) affirmed the relevance of the six ACAP scale elements but pointed out a minor controversy that the normative elements not as much focused on by researchers who have established existence of the paradigms of agriculture in the ACAP scale applied more to women in SA than to men. This could have important gender implications for research, policy, and education to facilitate SA practice. A major controversy for the scale concerns contention of its unidimensionality or coherence of its elements as parts of an interrelated whole as in the concept of paradigm (Jackson-Smith \& Buttel, 2003). The researchers found using varimax factor rotation analysis two sub-scales based on 12 selected ACAP variables they named as 'environmentalism' and 'family-farmist' that predicted a set of SA practices adopted by a sample of farmers in Wisconsin State, USA. The sub-scales only comprised of the ecological and social/structural components of the "ACAP" scale. This finding has weaknesses however; the predictive ability of the sub-scales for farmer practices does not differ fundamentally from the one of the ACAP scale and the two subscales are slightly negatively correlated and cannot therefore predict the same construct (Muma, 2006).

There is a fundamental methodological problem with the studies and especially that of Jackson-Smith and Buttel (2003) mentioned already that attempted to establish the relationship between farmer paradigmatic positions and adopted agricultural practices except those of Beus and Dunlap (1991, 1992, 1994). The theoretically required specification for attitudinal and multiple-act behavioral relationship is to relate summated paradigm variables to summated behavioral (farming practices) variables or individual attitude variables to specific behavioral variables. The requirement for this principle varied among the studies and their results may be in question. Further, there could be a methodological problem in adoption studies and paradigms in that some studies have not used rigorous techniques to classify farmers as sustainable agriculture farmers or not. The issue of variability of farmers' stages of adoption of agricultural practices may necessitate the need to stratify farmers on this variable in studies of agricultural paradigms. This calls into question the accuracy of findings of both the studies which support and those which contradict the Beus and Dunlap (1991, 1994) findings on the ACAP scale.

Dunlap, et al. (2000 cited in Welsh \& Rivers, 2011), did address Jackson-Smith's and Buttel's (2003) contention 
against the unidimensionality of the scale. Dunlap, et al. indicated that a paradigm scale may not be unidimensional for some diverse populations in developing the New Ecological Paradigm (NEP) scale. NEP has the ecological dimension in the ACAP scale (Welsh \& Rivers, 2011). They concluded that when further analysis of the variables of a scale by principal components and reliability analyses result in mainly one major dimension (larger Eigenvalue) and a high corrected item-total correlation and coefficient alpha, then a scale can be regarded as unidimensional. Trobe and Acott (2000) also developed a modified valid NEP scale agreeing with Dunlap et al. (2000).

To the best of our knowledge, no study using the ACAP scale has investigated the construct validity of the ACAP scale using agriculture teacher population in the NCR. Analyzing construct validity of the scale can be an important first step in guiding predictive studies on the teaching of agricultural curriculum and whether infusion of SA in the agriculture curriculum can contribute significantly to the broader goals of society (Muma, 2006). Such a contribution is needed to resolve the current problems such as environmental pollution and food safety in the agricultural industry (Muma et al., 2010). The study objectives were to analyze for the self-made ACAP scale:

\section{Alpha Coefficient}

2. Corrected item-total correlations; and

3. Rotated varimax factor principal components coefficients

\subsection{Methodology}

\subsubsection{Population and Sample}

The population was made up of 2,904 high school agriculture teachers. The teachers were from the NCR states (Muma et al., 2010) (Table 1). The sampling frame error was controlled for by use of an updated list of teachers (Muma et al., 2010). Most teachers taught plant science, soil science and agronomy. They were natural science teachers and were assumed to be similar. A random sample of 844 teachers was drawn from the 12 states and stratified by the teacher population of a state.

\subsubsection{Data Collection}

The Tailored Design Method of Dillman (2000) was employed. Just one reminder was given to non-respondent teachers to return the completed questionnaires because of resource constraints. There were a total of 239 useable questionnaires returned. This represented a $28 \%$ response rate. Early and late respondents were compared on the research variables to control for non-response error. The difference between the two groups on the main research variable was not statistically significant (Muma et al., 2010) (Table 2). Because there was no statistically significant difference between the two groups, the findings were generalized to the target population (Linder, Murphy, \& Briers, 2001; Muma et al., 2010).

\subsubsection{Scale Construction}

An Alternative-Conventional Agriculture Paradigm scale was self-developed for the SA beliefs scale. The scale is based on the six elements that distinguish respondent beliefs between SA and CA (Beus \& Dunlap, 1991 cited in Muma et al., 2010). A total of 20 items were included in the self-administered questionnaire by drawing at least 3 items from each of the six elements of SA/CA paradigms. Research literature on beliefs/perceptions of farmers, the public, and teachers regarding SA practice and perceptions of selected SA practices were used to generate all elements of the SA construct. Thus the construct validity for the instrument was partly established (Beus \& Dunlap, 1990, 1991, 1992, 1994 cited in Muma, 2006). The number of 20 items included in the scale was relatively large. According to Lawler (1967 cited in Muma et al., 2010), this ensured the construct was measured validly and completely. Two professors and a panel of 9 graduate students from the Agricultural Education and Studies Department at Iowa State University established instrument content and face validity. All were familiar with SA in the NCR.

The mentioned panel judged content of SA elements in the scale complete in relation to NCR. The panel thus determined content validity for the instrument (Muma et al., 2010) (Table 3). The adequate number of items included in the scale and thus a multiplicity of traits or factors representative of the entire universe SA construct ensured the instrument achieved content vality (Muma, 2006). A pilot-study on a random sample of 48 high school agriculture teachers in Iowa State was used to determine inter-item consistency for the instrument (Muma et al., 2011). The teachers were excluded from the main study. One item was deleted for having a relatively low inter-item correlation. 


\subsubsection{Analysis of Data}

The following statistics were generated from data analysis: frequencies, percentages, means, standard deviations, mean item, mean inter-item, and corrected item total correlations, coefficient alpha, Eigenvalues and principal component coefficients (Muma et al., 2011). Two-tailed non-directional null hypotheses were tested using $\alpha=$ 0.05 level of significance. Data were analyzed using SPSS $®$ and SAS®.

\section{Results}

The research population and sample data are summarized (Table 1). Table 2 summarizes how response error was controlled for. Since there was similarity between the two groups on the main research variable of teacher beliefs or paradigms of SA/CA, results are generalized to the target population (Muma et al., 2010).

Table 1. Population, samples and response rates of high school agriculture teachers by states in the NCR

\begin{tabular}{|c|c|c|c|c|c|c|}
\hline \multirow[t]{2}{*}{ State } & \multicolumn{2}{|c|}{ Population and Sample } & \multicolumn{2}{|c|}{$\begin{array}{c}\text { Sample Adjusted } \\
\text { for Low Responses }\end{array}$} & \multicolumn{2}{|c|}{ Response Rates } \\
\hline & Number of Teachers, $N$ & Proportional Sample, $n(\%)$ & $n$ & $\%$ & $n$ & Return $\%$ \\
\hline Illinois & 315 & $80(10.81)$ & 80 & 9.48 & 21 & 26.25 \\
\hline Indiana & 243 & $62(8.38)$ & 57 & 6.75 & 17 & 29.82 \\
\hline Iowa & 178 & $45(6.13)$ & 62 & 7.35 & 18 & 29.03 \\
\hline Kansas & 181 & $46(6.23)$ & 56 & 6.64 & 18 & 32.14 \\
\hline Michigan & 67 & $17(2.30)$ & 40 & 4.74 & 8 & 20.00 \\
\hline Minnesota & 239 & $61(8.23)$ & 62 & 7.35 & 11 & 17.74 \\
\hline Missouri & 427 & $109(14.70)$ & 104 & 12.32 & 28 & 26.92 \\
\hline Nebraska & 132 & $34(4.59)$ & 60 & 7.11 & 21 & 35.00 \\
\hline North Dakota & 237 & $61(8.16)$ & 61 & 7.22 & 6 & 9.84 \\
\hline Ohio & 492 & 125 (16.94) & 118 & 13.98 & 48 & 40.68 \\
\hline South Dakota & 80 & $20(2.75)$ & 60 & 7.11 & 18 & 30.00 \\
\hline Wisconsin & 313 & $80(10.78)$ & 84 & 9.95 & 27 & 32.14 \\
\hline Total & 2,904 & $740(100)$ & 844 & 100 & 240 & 28.44 \\
\hline
\end{tabular}

The instrument was analyzed for reliability and inter-item consistency (Muma et al., 2011). The mean inter-item total correlation was .20 (Table 3). The proportion of items with mean inter-item correlation greater than .25 was $30 \%$ (results not shown) and was greater than for the 12-item scale which was at 17\% (Jackson-Smith and Buttel, 2003). The proportion of items with mean inter-item correlation less than .1 was $20 \%$ (results not shown) and was slightly greater than for the 12 -item scale (17\%). Cronbach's Coefficient Alpha that measures reliability (mean of all possible split-half correlations or reliabilities) of the instrument was 0.82 (.83 standardized), representing a relatively high internal instrument consistency.

Table 2. Comparison of early and late respondents of high school agriculture teachers from the NCR states on research variables

\begin{tabular}{|c|c|c|c|c|c|c|c|}
\hline \multirow{2}{*}{ Variable } & \multicolumn{3}{|c|}{ Early Respondents } & \multicolumn{3}{|c|}{ Late Respondents } & \multirow{2}{*}{$t$-test } \\
\hline & $n$ & Mean & SD & $n$ & Mean & $\mathrm{SD}$ & \\
\hline Extent sustainable agriculture taught & 117 & 3.15 & 0.70 & 110 & 3.17 & 0.78 & -0.18 \\
\hline Years teacher taught agriculture & 122 & 16.07 & 10.05 & 117 & 16.56 & 9.83 & -0.38 \\
\hline Extent methods used for teaching SA & 119 & 3.06 & 0.69 & 114 & 3.03 & 0.76 & 0.38 \\
\hline Beliefs about sustainable agriculture & 119 & 3.66 & 0.45 & 112 & 3.65 & 0.41 & 0.11 \\
\hline Perceptions about sustainable agriculture & 117 & 3.90 & 0.59 & 109 & 3.88 & 0.53 & 0.28 \\
\hline Years teacher lived full-time on a farm & 119 & 20.16 & 16.64 & 115 & 17.69 & 15.72 & 1.17 \\
\hline Years teacher worked full-time on a farm & 120 & 12.20 & 14.73 & 114 & 10.50 & 12.92 & 0.94 \\
\hline Years teacher lived part-time on a farm & 119 & 8.18 & 12.55 & 115 & 11.42 & 14.35 & -1.84 \\
\hline Years teacher worked part-time on a farm & 119 & 12.18 & 13.85 & 115 & 16.88 & 15.17 & $* 2.47$ \\
\hline
\end{tabular}

Source: Adapted from Muma, 2006

Note: $\mathrm{SA}=$ sustainable agriculture; $n=$ number of teachers completing questionnaire; $t$-test $=t$-test statistic; $\mathrm{SD}=\mathrm{Standard}$ deviation; $*=t$-statistic significant $(p<.05)$. 
The self-made instrument exhibited relatively stronger instrument reliability comparable to the 12 -item scale with its two subscales which were relatively lower at, respectively, .72, .68 and .54 (Jackson-Smith and Buttel, 2003) but not to the 24-item scale (.88) (Beus \& Dunlap, 1991) . Corrected item-total correlations was computed to further assess the internal consistency and coherence of the self-made ACAP scale. The value of the mean item-total correlation was .40. This was greater than the value for the 12 -item scale (.35) but less than the value for the 24-item (.46) ACAP scale (Table 3).

Table 3. High school agriculture teacher scores on corrected item-total correlations, mean-item total correlations, mean inter-item correlations, and coefficient alpha for the self-made ACAP scale

\begin{tabular}{|c|c|c|c|}
\hline Sustainable Agriculture Belief Statement & Mean & SD & $\begin{array}{l}\text { Corrected item-total } \\
\text { correlation }\end{array}$ \\
\hline 1. Promotion of healthy soils is important for SA & 2.68 & 1.02 & .57 \\
\hline 2. SA conserves natural resources for future generations & 3.45 & 1.02 & .69 \\
\hline 3. Crop rotation promotes achievement of SA & 3.85 & .89 & .41 \\
\hline 4. SA promotes regeneration of renewable natural resources & 3.58 & .89 & .57 \\
\hline 5. SA values nature for its sake & 3.93 & .80 & .32 \\
\hline 6. Agricultural knowledge from extension is important for the success of SA & 3.51 & 1.00 & .51 \\
\hline $\begin{array}{l}\text { 7. Knowledge exchange on locally designed technologies among farmers } \\
\text { promotes SA }\end{array}$ & 3.62 & .98 & .35 \\
\hline 8. Integrating crops with livestock farming promotes SA & 3.22 & 1.09 & .57 \\
\hline 9. Local agricultural practices promote success of SA & 3.55 & .85 & .50 \\
\hline 10. Innovations in agricultural technology promotes success of SA & 3.10 & 1.04 & .26 \\
\hline 11. SA enhances local processing of agricultural produce & 3.90 & .75 & .44 \\
\hline 12. SA promotes local marketing of agricultural produce & 3.45 & .90 & .50 \\
\hline 13. SA promotes specialized crop and livestock farming & 3.48 & .85 & .31 \\
\hline $\begin{array}{l}\text { 14. Local knowledge of farming in a community is an indication of sustainability } \\
\text { in agriculture }\end{array}$ & 3.93 & .82 & .55 \\
\hline 15. Rural landscape quality and aesthetics are emphasized in SA practices & 3.94 & .91 & .32 \\
\hline 16. SA reduces reliance on external input sources & 4.24 & .90 & .28 \\
\hline 17. SA increases returns to farm labor & 4.15 & .87 & .24 \\
\hline 18. Farm-size is related to the intensity of farm management needed to attain SA & 4.14 & .98 & .22 \\
\hline 19. The size of a community influences SA development & 3.87 & .73 & .31 \\
\hline 20. SA aims at low farm capital investment and technology & 3.55 & .91 & .08 \\
\hline Mean item-total correlations & & & .40 \\
\hline Mean inter-item total correlations & & & .20 \\
\hline Coefficient Alpha & & & .82 \\
\hline
\end{tabular}

Source: Adapted from Muma, Martin and Shelley et al., 2010

Note $: \mathrm{SD}=$ Standard deviation

The relatively strong internal consistency of the self-made 20-item scale compares to the internal consistency for the 24-item ACAP scale used by Rasmussen \& Kaltoft 2002) to gauge agricultural university faculty and student SA/CA paradigms at a university in Denmark. The mean item-total correlations for the various study groups in the above study were comparable to the mean value found in this study and ranged from .38 to .67. Some of the generic variables in the self-made scale in this study that match the same variables under the six elements of the ACAP scale (Beus \& Dunlap, 1991; Rasmussen \& Kaltoft, 2002) had relatively high item-total correlations of at least 20 .

The following generic variables each of which can be grouped into approximately the same category in the six elements of the ACAP scale (Beus \& Dunlap, 1991, 1992) had relatively high item-total correlations, respectively, in this and Rasmussen and Kaltoft's (2002) studies (numbers represent item number labels on Table 3 in this study; letters represent item labels in the original Beus and Dunlap's, 1991 study); item 3, L; item 4, S; item 16, C; and item 17, W. It is important to note that although items labeled G, P, T and V in the ACAP scale (Beus and Dunlap) were found to have among the lowest item-total correlation values in the Rasmussen and Kaltoft's (2002) study, the variables had relatively high item-total correlation values in the Beus and Dunlap's study (at least .32) and this study (at least .20). The variables which can be regarded as equivalents within the six elements of the ACAP scale which had relatively high item-total correlations (at least .20) in this and Beus and Dunlap's (1991) studies were (numbers represent item number labels on Table 3 in this study; letters represent 
item labels in the original Beus and Dunlap's, 1991 study); item 2, Q; item 3, L; items 4, 5, N,S; item 8, P; items 9, 14, G; items 11, 12, U; item 13, T; item 16, C; item 18, E, I, O; item 19, A, H.

Table 4. Results of factor analysis for high school agriculture teachers using self-made 20-item Alternative-Conventional Agriculture Scale items

\begin{tabular}{|c|c|c|c|c|c|c|c|}
\hline \multirow[t]{2}{*}{ *Sustainable Agriculture Belief Statement } & \multirow[b]{2}{*}{ Unrotated factor $^{\mathrm{a}}$} & \multicolumn{6}{|c|}{ Varimax rotated factor loadings ${ }^{b}$} \\
\hline & & 1 & 2 & 3 & 4 & 5 & 6 \\
\hline 1 & .80 & .76 & .33 & .10 & .14 & .02 & .14 \\
\hline 2 & .69 & .76 & .15 & .09 & .15 & .13 & -.03 \\
\hline 3 & .69 & .70 & -.07 & .00 & -.18 & .18 & .20 \\
\hline 4 & .69 & .69 & .31 & -.01 & .22 & .04 & .04 \\
\hline 5 & .63 & .68 & .08 & .34 & -.04 & .04 & .11 \\
\hline 6 & .61 & .40 & .30 & .37 & .16 & .12 & .02 \\
\hline 7 & .61 & .00 & .63 & .16 & -.22 & .27 & .19 \\
\hline 8 & .56 & .26 & .58 & .30 & .03 & -.04 & .17 \\
\hline 9 & .52 & .15 & .58 & .04 & -.33 & .23 & -.23 \\
\hline 10 & .51 & .42 & .49 & .29 & .19 & -.22 & -.15 \\
\hline 11 & .41 & .20 & .46 & -.07 & .24 & .00 & .22 \\
\hline 12 & .07 & .25 & -.09 & .75 & -.21 & .10 & -.17 \\
\hline 13 & .43 & .02 & .30 & .72 & .24 & .01 & .12 \\
\hline 14 & .32 & .09 & .23 & .56 & .24 & .25 & .39 \\
\hline 15 & .35 & -.06 & -.08 & .03 & .76 & .17 & -.07 \\
\hline 16 & .41 & .26 & .02 & .11 & .74 & -.05 & -.05 \\
\hline 17 & .33 & .09 & .06 & .15 & .08 & .80 & .12 \\
\hline 18 & .23 & .12 & .10 & .01 & .04 & .75 & -.19 \\
\hline 19 & .32 & .14 & .16 & .01 & -.08 & -.03 & .78 \\
\hline 20 & .39 & .49 & -.04 & .09 & -.09 & -.13 & .50 \\
\hline Initial Eigenvalue & & 5.22 & 1.69 & 1.65 & 1.33 & 1.09 & 1.06 \\
\hline Rotation sums of squared loadings & & 3.45 & 2.1 & 1.92 & 1.71 & 1.60 & 1.40 \\
\hline Percent of variance & & 26.11 & 8.50 & 8.26 & 6.62 & 5.46 & 5.31 \\
\hline
\end{tabular}

Source: Own compilation

Note: ${ }^{*}=$ Itemized beliefs statement about sustainable agriculture are labeled in Table $3 ;{ }^{\mathrm{a}}=$ Unrotated factor components; $^{\mathrm{b}}=$ Rotated principal components; $\mathbf{0 . 4 0}, \mathbf{0 . 5 0}, \mathbf{0 . 6 0} \ldots=$ high rotated varimax factor loadings

All the above indicated that on average, all items in the 20-item scale represented the same underlying universal construct as compared to the Beus and Dunlap's (1991) scale than to the Jackson-Smith and Buttel's (2003) scale This is so given that the mean figure for the 24-item scale was for the full range of known groups combining alternative and conventional agriculture adherents and statewide farmers in Washington State in the Beus and Dunlap's (1991) study. Teachers being not members of the two extreme camps in the SA/CA adherents can be expected to score a relatively lower value of corrected item-total correlation on an ACAP scale and coefficient alpha than would a population comprising the full range of groups in the SA/CA debates (Beus \& Dunlap, 1991, 1994). It is equally important to note in particular that the scoring patterns for some individual items in the ACAP scale were not necessarily the same in the self-made 20-item and 12-item scales.

In an approach similar to Beus and Dunlap's (1991) analysis of the ACAP scale for predicting adherence to SA/CA, a principal components analysis was performed to test for the construct validity of the 20-item self-made ACAP scale (Table 4). Unrotated and rotated factor loadings for individual items are reported. Ten out of 20 items in this study had unrotated factors less than .5 while the other half had unrotated factors greater than .5 . At least 7 items (35\%) out of the 20 items had unrotated items with coefficients greater than .6. Beus and Dunlap's ACAP scale had $6(30 \%)$ out of 24 items with unrotated loadings greater than .5 and only 4 (20\%) items with unrotated loadings greater than .6. Jackson-Smith and Buttel's (2003) 12-item scale had 5 items (42\%) with unrotated loadings less than .5 and only $2(17 \%)$ items with unrotated loadings greater than .6. The self-made ACAP scale fared better in the first unrotated factor loadings on most items than had both Beus and Dunlap's (1991) and Jackson-Smith and Buttel's (2003) ACAP scales which had relatively similar results regarding unrotated first factor loadings on most of the items on each scale. The two latter scales had also similar results 
regarding variance explained in the answer sets of each scale which was, respectively, one quarter of variance.

A varimax factor analysis was also performed on the self-made scale to help assess the scale for potential multi-dimensionality. Six factors were extracted (Table 4). Eight of the 20-item self-made scale items loaded on the first rotated factor; five and three variables, respectively, loaded on the second and third rotated factors while the fourth, fifth and the last rotated factors had two variables loading on each factor. Only the rotated first factor had a larger Eigenvalue than .5. The rest of the factors had Eigenvalues between 1.06 and 1.69. The first factor had explained over 26 percent of variance in the items in the self-made scale while the rest of the factors each explained a variance of under 10 percent in the items. Beus and Dunlap (1991) had extracted five rotated factors from the 24 item ACAP scale. Items 6, 10, 11, 14 and 20 had factor loadings of about the same strength in at least two or more factors suggesting unidimensionality of the scale according to Beus and Dunlap (1991) and Dunlap and Van Liere (2000). These findings are comparable to Beus and Dunlap's (1991) and Dunlap and Van Liere's (2000) findings on the ACAP scale.

\section{Discussion}

In general, the findings indicate that the self-made instrument based on the six elements of the SA/CA paradigms has a relatively high; alpha coefficient (.82), mean item-total correlation (.40), and a main unrotated factor or principal component explaining over 26 percent of variance of the scale items. These results are similar to the findings of Beus and Dunlap (1991) and Rasmussen and Kaltoft (2002) on the ACAP scale. The findings contradict the study of Jackson-Smith and Buttel on their 12-item ACAP scale.

The relatively high coefficient alpha, mean item total correlation, and unrotated and rotated first factors with modest numbers of items loading on them means that there is mainly one underlying construct in the instrument. It also means that the teacher population in the NCR holds views and attitudes about SA which are consistent. The teacher attitudes constitute an agricultural paradigm supporting SA practice. Further, the instrument items are coherent as components of a whole and are related. However, the teacher population seems not to hold stronger paradigmatic views as the ACAP scale can be expected to predict because of the relatively low mean item-total correlation and coefficient alpha realized for the instrument compared to what was found for the ACAP scale in both the Beus and Dunlap (1991) and Rasmussen and Kaltoft (2003) studies. This should be expected because agriculture teachers are not strong adherents of the two agricultural paradigms who can be expected to make extreme and polar scores on the ACAP scale. Strong adherents of SA/CA paradigms such as proponents of the two paradigms are in contact with each other and set social goals and means to realize them and clarify new advocated values and practices from the old ones (Beus \& Dunlap, 1991). Therefore, the findings of Jackson-Smith and Buttel (2003) on the ACAP scale are not supported in this study.

\section{Conclusion}

The relatively high; alpha coefficient (.82), mean item-total correlation (.40), and a main unrotated factor or principal component explaining over 26 percent of variance of the scale items implies the instrument has construct validity. The instrument can therefore be used to preliminarily gauge the paradigmatic orientation of agriculture teachers in the NCR or other regions of the US since the items used for construction of the scale are generic. Because there was no known groups supporting the two polar paradigms of agriculture to help further confirm the construct validity of the instrument, more research with the instrument with such groups and farmers is necessary to establish the validity of the scale. The instrument can also be improved by deletion or reconstruction of the variables with the lowest item-total correlations to increase item consistency and coherence and its validity.

\section{Acknowledgements}

This paper is a product of the Iowa Agriculture and Home Economics Experiment Station, Ames, Iowa, Project No. 3613, and was sponsored by the Hatch Act and State of Iowa. We thank Jennifer Krueger and Jonathan Brunt for their help in reviewing the final draft of this manuscript.

\section{References}

Abaidoo, S., \& Dickinson, H. (2009). Alternative and conventional agricultural paradigms: Evidence from farming in South Saskatchewan. Rural Sociology 67(1), 114-131. https://doi.org/10.1111/j.1549-0831.2002.tb00096.x

Allen, J. C., \& Bernhardt, K. (1995). Farming Practices and Adherence to an Alternative-Conventional Agriculture Paradigm. Rural Sociology, 60(2), 297-309. https://doi.org/10.1111/j.1549-0831.1995.tb00574.x

Beus, C. E., \& Dunlap, R. E. (1990). Conventional versus alternative agriculture: The paradigmatic roots of the 
debate. Rural Sociology, 55, 590-616. https://doi.org/10.1111/j.1549-0831.1990.tb00699.x

Beus, C. E., \& Dunlap, R. E. (1991). Measuring adherence to alternative versus conventional agricultural $\begin{array}{llllll}\text { paradigms: } & \text { A }\end{array}$ https://doi.org/10.1111/j.1549-0831.1991.tb00442.x

Beus, C. E., \& Dunlap, R. E. (1992). The Alternative-Conventional Agriculture Debate: Where Do Agricultural Faculty Stand? Rural Sociology, 57, 363-380. https://doi.org/10.1111/j.1549-0831.1992.tb00470.x

Beus, C. E., \& Dunlap, R. E. (1994). Agricultural paradigms and the practice of agriculture. Rural Sociology, 59(4), 620-635. https://doi.org/10.1111/j.1549-0831.1994.tb00551.x

Chiappe, M. B., \& Flora, C. B. (1998). Gendered elements of the alternative agriculture paradigm. Rural Sociology, 63(3), 372-393. https://doi.org/10.1111/j.1549-0831.1998.tb00684.x

Dillman, D. A. (2000). Mail and internet surveys: The tailored design method (2nd ed.). New York: Wiley. https://doi.org/10.1177/003435520104400309

Dunlap, R. E., Van Liere, K. D., Mertig, A. G., \& Jones, R. E. (2000). New trends in measuring environmental attitudes: Measuring endorsement of the new ecological paradigm: A revised NEP scale. Journal of Social Issues, 56, 425-442. https://doi.org/10.1111/0022-4537.00176

Jackson-Smith, D. B., \& Buttel, F. H. (2003). Social and Ecological Dimensions of the Alternative-Conventional $\begin{array}{lllll}\text { Agricultural Paradigm } & \text { Scale. Rural 5ociology }\end{array}$ https://doi.org/10.1111/j.1549-0831.2003.tb00149.x

Lawler, III E. E. (1967). The multitrait-multi rater approach to measuring managerial job performance. Journal of Applied Psychology, 51, 369-381. https://doi.org/10.1037/h0025095

Lindner, J. R., Murphy, T. H., \& Briers, G. E. (2001). The handling of nonresponse in agricultural education. Proceedings of the 28 $8^{\text {th }}$ Annual National Agricultural Education Research Conference, 28, 233-245, December 12, New Orleans, LA. https://doi.org/10.5191/jiaee.2002.09307

Muma, M. A. (2006). Sustainable agriculture and the perceptions of high school agriculture teachers in the North Central Region of the United States (Unpublished doctoral dissertation). Iowa State University, Ames, Iowa. https://doi.org/10.1080/10440041003680312

Muma, M., Martin, R., Shelley, M., \& Holmes Jr., L. (2010). Sustainable agriculture: Teacher beliefs and topics taught. Journal of Sustainable Agriculture, 34(4), 439-539. https://doi.org/10.1080/10440041003680312

Muma, M., Martin, R., \& Shelley, M. (2011). Teacher beliefs and the extent to which sustainable agriculture is taught in high school. Journal of Sustainable Agriculture, 35(7), 804-822. https://doi.org/10.1080/10440046.2011.606494

Petrzelka, P., \& Korsching, P. F. (1996). Farmers' Attitudes and Behavior towards Sustainable Agriculture. Journal of Environmental Education, 28(1), 38-44. https://doi.org/10.1080/00958964.1996.9942814

Rassmussen, J., \& Kaltoft, P. (2003). Alternative versus conventional attitudes in higher agricultural education. Biological Agriculture and Horticulture, 20, 347-363. https://doi.org/10.1080/01448765.2003.9754978

Rickson, R. E., Saffigna, P., \& Sanders, R. (1999). Farm Work Satisfaction and Acceptance of Sustainability Goals by Australian Organic and Conventional Farmers. Rural Sociology, 64(2), 266-283. https://doi.org/10.1111/j.1549-0831.1999.tb00018.x

Trobe, H. L. La, \& Acott, T. G. (2000). A modified NEP/DSP environmental attitudes scale. The Journal of Environmental Education 32(1), 12-20. $\quad$ Retrieved from https://www.tandfonline.com/doi/abs/10.1080/00958960009598667

Welsh, W., \& Rivers, R. Y. (2011). Environmental management strategies in agriculture. Agriculture and Human Values, 28, 297-302. https://doi.org/10.1007/s10460-010-9285-7

Wheeler, S. A. (2008). What Influences Agriculture Professional's Views Towards Agriculture? Ecological Economics, 65(1), 145-154. https://doi.org/10.1016/j.ecolecon.2007.05.014

\section{Copyrights}

Copyright for this article is retained by the author(s), with first publication rights granted to the journal.

This is an open-access article distributed under the terms and conditions of the Creative Commons Attribution license (http://creativecommons.org/licenses/by/4.0/). 